\title{
A dialética da natureza na produção do espaço na Praia do Saco, litoral sul de Alagoas/Brasil
}

\section{The dialectic of nature in the production of space at the Praia do Saco, south coast of Alagoas/Brazil}

\author{
Rennisy Rodrigues Cruz ${ }^{1}$ \\ Mariana Zerbone Alves de Albuquerque ${ }^{2}$ \\ Edvânia Torres Aguiar Gomes ${ }^{3}$
}

\author{
Palavras-chave: \\ Unidades de Conservação \\ Empreendimentos Imobiliários \\ Natureza \\ Capitalismo \\ Desterritorialização
}

\begin{abstract}
Resumo
Este artigo tem por objetivo investigar os impactos socioambientais ocasionados com a expansão de empreendimentos imobiliários e analisar a relação sociedade e natureza no processo de produção do espaço da Praia do Saco no Município de Marechal Deodoro - AL. No processo de produção do espaço do litoral de Alagoas nota-se a expansão de empreendimentos imobiliários em áreas de conservação ambiental associados à privatização de acessos a praia, à desterritorialização de comunidades, e à destruição e apropriação da natureza por loteamentos e condomínios. Nesse sentido, fez-se necessário tecer uma discussão teórica sobre a produção do espaço e a dialética da natureza, como também a elaboração de uma análise específica da produção do espaço na Praia do Saco, identificando os vetores de transbordamento da capital Maceió para o Litoral Sul de Alagoas, as ações, os agentes e as transformações socioespaciais, além das irregularidades e os impactos socioambientais a fim de uma investigação crítica sobre a dinâmica contemporânea desse espaço. Como parte dos procedimentos metodológicos foram realizadas visitas a campo para observação, análise da área em questão, confeç̧ão de fotografias e realização de entrevistas. Deste modo, constatou-se que este processo de expansão imobiliária no litoral sul da Região Metropolitana de Maceió tem reproduzido o processo de acumulação por despossessão, pois, áreas são apropriadas pelos empreendedores imobiliários, o que gera a expulsão direta ou indireta das comunidades tradicionais, além de ocasionar um forte impacto socioambiental na área pela exploração irregular do solo.
\end{abstract}

\begin{abstract}
This article aimed to investigate the social and environmental impacts caused by the increase of real estate projects and to analyze the relationship between society and nature in the Praia do Saco space in the city of Marechal Deodoro - Alagoas/Brazil. In the space on the coastal area of Alagoas is noted an increase of real estate ventures in protected areas, where the access to the beach becomes
\end{abstract}

1Pós - Graduação em Desenvolvimento e Meio Ambiente - PRODEMA - UFPE. rrcambiental@gmail.com 2Universidade Federal Rural de Pernambuco - UFRPE. mzerbone@hotmail.com

${ }^{3}$ Universidade Federal de Pernambuco - UFPE. edvaniatorresaguiar@hotmail.com 
private, the communities are displaced, and the nature is destroyed and replaced by allotments and gated communities. In this sense, we developed a theoretical discussion about the production of space and the dialectic of nature. It was also necessary to make a specific analysis of produced space in Praia do Saco, identifying the vectors of overflowing from the capital Maceió to the South Coast of Alagoas, socio-spatial actions, agents and transformations, as well as irregularities and socio-environmental impacts in order to investigate critically the contemporary dynamics of this space. Field visits were made for observation and analysis of the area in question, to take photographs and conduct interviews. Thus, it was found that this process of real estate increase in the southern coast of the Metropolitan Region of Maceió has reproduced the accumulation by dispossession, because real estate developers appropriate areas, generating, directly or indirectly, a displacement of traditional communities. Besides these actions are causing a strong social and environmental impact in the area by the irregular exploitation of the soil.

\section{INTRODUÇÃO}

A construção de empreendimentos imobiliários em unidades de conservação, reservas ecológicas ou em áreas com "amenidades" ambientais como praias, florestas, rios, lagoas, apesar de haver restrições normativas, é recorrente no Brasil. No processo de produção do espaço do litoral de Alagoas nota-se a expansão desses empreendimentos em áreas de conservação ambiental associados à privatização de acessos a praia, à desterritorialização de comunidades, e à destruição e apropriação da natureza por loteamentos e condomínios. Partindo dessa premissa, neste artigo tem-se como objetivo investigar os impactos socioambientais ocasionados pela expansão de empreendimentos imobiliários e analisar a relação sociedade e natureza no processo de produção do espaço da Praia do Saco, no Município de Marechal Deodoro, Alagoas.

O município em questão faz parte da região metropolitana de Maceió e está inserido no Complexo Estuarino Lagunar Mundaú/Manguaba - CELMM, contendo partes de seu território circunscritos nas Unidades de Conservação - UC (Área de Proteção Ambiental de Santa Rita - APASR e na Reserva Ecológica do Saco da Pedra - RESEC), ambas estaduais. O fato da Praia do Saco está inserida em uma área de unidades de conservação e ser lócus de expansão imobiliária chama atenção para análise. Nesse sentido buscou-se compreender os processos de licenciamento para instalação e regularização desses empreendimentos, os impactos socioambientais gerados, e a relação da natureza e sua idealização no que tange a valorização desses imóveis.

Especificamente na Praia do Saco observa-se uma contradição em relação à apropriação da natureza, pois ao mesmo tempo em que é uma área de unidade de conservação e que teoricamente deveria ser conservada, esta mesma natureza sofre impacto direto dos empreendimentos que a utiliza como um fetiche que agrega valor aos imóveis, associando o discurso da qualidade de vida, do ar puro, do lazer e sustentabilidade. Efetivamente, a expansão desses tipos de empreendimentos em áreas costeiras e de proteção ambiental são geradores de impactos negativos nesta mesma natureza que é determinante para a valorização dos imóveis.

Essas contradições são estratégicas na reprodução e acumulação do capital a partir da produção de equipamentos imobiliários, os quais passam a ser centrais na produção do espaço urbano, criando áreas segregadas através do processo de espoliação. Este processo desterritorializa comunidades que historicamente ocupam essas áreas, ampliam a especulação imobiliária, além de causar problemas ambientais, como a degradação de áreas protegidas, falta de água e saneamento.

Para realização desta pesquisa, a fim de compreender e analisar os aspectos referidos foi realizada uma revisão de literatura pautada na discussão sobre natureza e produção do espaço como sendo as principais categorias para análise do problema apresentado. Como procedimentos metodológicos foram realizadas visitas a campo para observação, análise da área em questão, confecção de fotografias e realização de 
entrevistas abertas com representantes da associação de moradores da Massagueira e com os promotores imobiliários da Praia do Saco.

A entrevista realizada com os representantes da associação de moradores foi no formato de um diálogo em grupo e aberto, que teve como questionamento central quais são os impactos da expansão dos loteamentos na praia do Saco e como isso tem interferido em suas atividades cotidianas. Já em relação aos promotores imobiliários, foi entrevistado um universo de seis promotores, com o intuito de fazer levantamento das informações dos empreendimentos, como a proposta do empreendimento, o preço do metro quadrado, o público alvo, a quantidade de produtos comercializáveis e as questões referentes ao licenciamento ambiental.

Foram realizadas visitas aos órgãos gestores, como o Instituto de Meio Ambiente de Alagoas, Secretaria do Meio Ambiente e dos Recursos Hídricos de Alagoas, Secretaria de Pesca, Agricultura e Meio Ambiente de Marechal Deodoro, para solicitação de documentos como Plano de Manejo, Plano de Diretor de Desenvolvimento Urbano, Estudos de Impacto Ambiental e Processos dos Empreendimentos.

\section{A DIALÉTICA DA NATUREZA NA PRODUÇÃO DO ESPAÇO}

A produção do espaço pode ser entendida como o processo de transformação da natureza a partir do trabalho humano. Como afirma Carlos (1999) o espaço é condição, meio e produto das relações sociais. A partir do momento que o homem se torna produtor do espaço, este passa a não se perceber como natureza, estabelecendo-se assim uma relação contraditória, desigual e dicotômica, entre sociedade e natureza. Ao mesmo tempo em que os elementos da natureza são as fontes de recurso para as ações do homem como ser social, são empecilhos para a expansão da obra humana, principalmente no que tange a expansão do espaço urbano, cada vez mais transformado e artificializado.

Lefebvre, em seu livro A Revolução Urbana, discute a relação sociedade-natureza e como ela passa a ser percebida pela sociedade urbana. Cabe destacar que a natureza, em função de sua raridade diante a transformação do espaço pelo homem na sociedade capitalista, se torna fetiche, não sendo uma natureza real e concreta, mas uma natureza idealizada pautada na presença do verde e da água como elementos cênicos que embelezam os espaços e remetem à ideia de qualidade de vida, em contradição à artificialização produzida pela sociedade. Nesse sentido Lefebvre afirma que:

Teoricamente, a natureza distancia-se, mas os signos da natureza e do natural se multiplicam substituindo e suplantando a "natureza real. Tais signos são produzidos e vendidos em massa. Uma árvore, uma flor, um ramo, um perfume, uma palavra, tornam- se signos da ausência: ilusória e fictícia presença. Ao mesmo tempo, a naturalização ideológica obceca. $\mathrm{Na}$ publicidade, a dos produtos alimentares ou têxteis, como a da moradia ou das férias, a referência à natureza é constante. Todos os "significantes flutuantes" que a retórica utiliza se agarram à sua representação para encontrar um sentido e um conteúdo (ilusórios). O que não tem mais sentido procura reencontrar um sentido pela mediação do fetiche "natureza" (LEFEBVRE, 2004, p.36).

Apesar desta relação contraditória, os elementos da natureza são cada vez mais utilizados como signos que agregam valor às mercadorias imobiliárias no processo de produção do espaço. É preciso ter claro que essa produção não se encerra em si, pois em uma sociedade capitalista ela está diretamente relacionada à acumulação do capital. Alfred Schimdt, ao analisar o conceito de natureza em Marx, afirma que:

La naturaleza es una categoría social, es decir lo que en un determinado estadio del desarrollo social vale como naturaleza, el modo en que ocurre la relación entre esta naturaleza y el hombre y la forma en que se produce el ajuste entre éste y aquélla y, por tanto, lo que la naturaleza tiene que significar en lo que respecta a su forma $y$ contenido, su alcance y objetividad, está siempre socialmente condicionado (SCHIMDT, 1977, p. 78).

A necessidade de expansão da produção e reprodução do espaço são condições inerentes ao processo para criar formas contínuas de extração da mais-valia. Harvey (2001, p. 52) afirma que "A expansão geográfica e a concentração geográfica são ambas consideradas produtos do mesmo esforço de criar novas oportunidades para acumulação do capital". No entanto, a produção do espaço para este fim está imbuída de diversas estratégias para agregar valor ao mesmo e 
garantir um maior lucro, na maioria das vezes com discursos distópicos, que são contraditórios em suas essências, como por exemplo a venda de loteamentos e condomínios os quais têm como central de suas propagandas ou até mesmo em seus nomes noções de uma natureza harmônica ou de sustentabilidade ambiental, mas a sua própria concepção já é uma ação predatória do ambiente em que vai ser instalado.

As parcelas do espaço são constituídas de arranjos naturais e artificiais, produto de um processo histórico de transformação tanto pela ação do homem como pela dinâmica da natureza. Essas parcelas do espaço se materializam como espaços singulares, com suas particularidades, porém inseridas em uma lógica de uma produção que não necessariamente é oriunda do local, mas do que Lefebvre chamaria de uma ordem distante, configurando espaços "raros" e seletivos". Nesse sentido Lencioni (2016, p. 30) afirma que "A análise do sítio e da posição relativas a uma dada parcela do espaço nos auxilia de maneira complementar a compreender a renda imobiliária, e no limite, a qualidade da raridade que algumas parcelas do espaço usufruem".

Quando se trata de valorização dos espaços para fins imobiliários utilizando o discurso de natureza, se imprime uma relação simbiótica entre os discursos dos promotores imobiliários e os desejos dos compradores, que se afinam num tom de sustentabilidade, mas enquanto que o primeiro visa o lucro, o segundo visa à distinção, a "seletividade" e paga mais caro para isso. Essa relação simbiótica é recorrente no processo de produção do espaço pelos agentes hegemônicos, como promotores imobiliários, os proprietários fundiários e o Estado, segregando do processo os agentes contra hegemônicos que lutam para produzir o espaço e resistir às ações hegemônicas que se expandem para acumulação, desterritorializando os demais grupos que não se afinam a esse processo de produção de espaço por espoliação.

A produção do espaço, principalmente em um país periférico como o Brasil, está pautada numa sociedade de classes, hierarquizada, em que os desejos e fetiches de poucos (os capitalistas) se sobrepõem às necessidades básicas de muitos (os trabalhadores), e nesse âmbito a natureza que pode ser fonte dos recursos para suprir essas necessidades básicas passa a ser restrita aos desejos daqueles que se apropriam dela como um fetiche idealizado.

\section{A PRODUÇÃO DO ESPAÇO DA MASSAGUEIRA}

A Massagueira, onde está localizada a Praia do Saco, é uma localidade do município de Marechal Deodoro no Estado de Alagoas. O município que faz parte da Região Metropolitana de Maceió, tem uma população estimada para $2017 \mathrm{em}$ 52.260 habitantes e uma área de $361,85 \mathrm{~km}^{2}$ com densidade demográfica de $138,62 \mathrm{hab} / \mathrm{km}^{2}$. O Índice de Desenvolvimento Humano Municipal IDMH é de 0.642, e o Produto Interno Bruno PIB per capita, é de $R \$ 29.071,13$, ocupando a posição de $2^{\circ}$ lugar em Alagoas (IBGE, 2010).

Marechal Deodoro faz parte do Complexo Estuarino Lagunar Mundaú-ManguabaCELMM, e contém em seu território áreas inseridas em duas Unidades de Conservação Área de Proteção Ambiental de Santa Rita APASR e Reserva Ecológica do Saco da Pedra RESEC. No município também está presente a maior ilha lacustre do Brasil (Ilha de Santa Rita), a praia do Francês, a praia do Saco e a prainha da Comunidade da Barra Nova.

Segundo informações do Plano Diretor de Desenvolvimento Urbano - PDDU, lei municipal $\mathrm{N}^{\circ}$. 919/2006 de Marechal Deodoro, a localidade da Massagueira insere-se, conforme art. 89 e art. 95, na Macrozona 3 - Santa Rita que compreende as áreas de Canais, e na área especial Macrozona 6 - Costeira, que abrange a faixa de praia e 24 metros do Mar Territorial de Marechal Deodoro.

Para compreender a produção contemporânea desse espaço, é importante entender o processo histórico de ocupação da área. Massagueira significa na língua indígena "o que foi alagadiço" e como era chamado o engenho que deu nome à localidade Heleno (2009). A formação histórica dessa comunidade não é diferente de outras partes do Brasil, por um lado tinha-se a natureza e do outro os primeiros habitantes, que ao longo do tempo foram dizimados e explorados sob a lógica da acumulação primitiva do capital com a formação de latifúndios. De acordo com Heleno (2009, p. 61) "Os que primitivamente viviam nas terras da Massagueira eram notáveis pescadores e exímios canoeiros, qualidades herdadas pelos habitantes nativos atuais"

Até a década de 1960 a Massagueira ainda era habitada por poucas famílias, algumas com casas simples, típicas de agricultores e pescadores que tiravam seu sustento da laguna e poucas casas construídas como segunda residência. Seu acesso não era pela então AL 101 Sul, dava-se de barco pela laguna e também por estradas no município de Marechal Deodoro, o que tornava essa área distante da capital, Heleno (2009).

A década de 1970 foi um marco divisor para o 
início da expansão do tecido urbano de Maceió em direção ao litoral sul do Estado de Alagoas. Com a implantação da Indústria Salgema em 1976, atual Braskem em Maceió, e em seguida com a construção da Rodovia AL/101 Sul, dos viadutos do Detran, Francês e da Barra de São Miguel em 1979 houve a intensificação do processo de urbanização com surgimento, a partir dos anos de 1980, de diversos empreendimentos imobiliários (casas de segunda residência, condomínios, loteamentos), acelerando as atividades turísticas e o aumento populacional no município de Marechal Deodoro, Alagoas (2015),

Contudo, em 1984 foi instituída a APA de Santa Rita que compreende áreas de Coqueiro Seco, Maceió e Marechal Deodoro, e em 1985 foi criada a Reserva Ecológica do Saco da Pedra em Marechal Deodoro, Alagoas (2015). Mesmo com a criação de áreas de conservação, ampliaram-se as indústrias e a infraestrutura local, com a duplicação da Salgema e a criação do Polo Cloroquímico nos tabuleiros de Marechal Deodoro em 1986 (VIEIRA, 1997).

A partir da década de 1980, após a construção da rodovia AL 101 Sul, percebe-se que a população rural de Marechal Deodoro diminuiu enquanto a urbana aumentou gradativamente e mais que duplicou a quantidade de pessoas que passaram a morar no município. Em 1980 a população total era de 22.696 habitantes, sendo 9.370 urbana e 13.325 rural, já em 2010 a população total do município era de 45.977, sendo a urbana 43.392 e a rural 2.585 com estimativa para 2019 de 51.901 habitantes, (IBGE, 2010).

Em 2010 o Ministério do Turismo cedeu recursos para a duplicação de mais de $20 \mathrm{~km}$ da rodovia AL 101 Sul, o que possibilitou a ampliação da conexão entre Maceió e Marechal Deodoro. Além de recursos do Ministério do Turismo,e do PRODETUR/NE, foram disponibilizadas emendas de bancada e contrapartida do Estado (AMA, 2009, apud MACHADO, 2016). O projeto possibilitou a nítida expansão do tecido urbano de Maceió em direção ao município de Marechal Deodoro.

A construção da AL 101 Sul e com ela as pontes e viadutos ligando Maceió ao litoral sul de Alagoas, foi determinante para a expansão do tecido urbano, inicialmente com a construção de bares e restaurantes na área de Massagueira, e posteriormente com loteamentos e condomínios residenciais, principalmente de casas de alto padrão na região da Praia do Saco, como será apresentado a seguir.
EMPREENDIMENTOS IMOBILIÁRIOS NA REGIÃO DA PRAIA DO SACO E A RELAÇÃO CONTRADITÓRIA COM A NATUREZA

A Praia do Saco, com aproximadamente de cinco quilômetros de extensão e distante 15 quilômetros de Maceió, tem sido atingida pela expansão urbana que transborda a capital e se materializa principalmente com a construção de loteamentos e condomínios de alto padrão. As áreas que estão sendo transformadas têm diversos atrativos naturais e de localização que agregam valor aos imóveis e são bastante explorados pelo marketing dos empreendimentos. A estética presente na natureza é utilizada nas propagandas, no nome dos empreendimentos e incorporada nos discursos dos agentes imobiliários associando os imóveis ao contato com a natureza que remete a qualidade de vida, como Parque Brumas do Francês, Brisas Mares do Sul, Enseada da Lagoa, e Ilha da Lagoa. Como afirma Haug, "a função que leva à abstração estética da mercadoria é a função e realização que obtém, na promessa estética de valor de uso, o seu meio motivador da compra, Haug (1996, p. 74).

Contudo, estes loteamentos e condomínios de alto padrão que vêm sendo construídos desde a década de 1990 estão inseridos totalmente na APA de Santa Rita, um local de instabilidade ambiental, com alto grau de vulnerabilidade por ser uma área de estuário lagunar com muita variação de maré, vegetação de restinga, presença de manguezais e mata atlântica, e uma fauna costeira específica, sendo local de desova de tartarugas.

Os empreendedores que atuam nesta área buscam se apropriar da beleza cênica, de infraestrutura adequada e de boa localização para a implementação de empreendimentos voltados para o público de alto padrão econômico.

Os principais empreendimentos foram construídos nas proximidades da praia do Saco como o residencial Ilha da Lagoa com vendas iniciadas em 2012 e o residencial Granville em 2008, porém ainda há unidades à venda. Enquanto que outros ainda estão em construção como na Massagueira de Baixo, como o Brisas Mares do Sul Flex Residence, às margens da Rodovia AL 101 Sul, o loteamento Enseada da Lagoa, em frente ao canal da Laguna Manguaba, e o Loteamento Parque Brumas do Francês na Praia do Saco, esse último será detalhado no decorrer desse artigo.

A construção e consolidação desses 
loteamentos vêm provocando vários problemas socioambientais na área, além de produzir, sob a lógica mecanicista, espaços segregados e que, em sua maioria, não atendem às normativas fundiárias e ambientais. No entanto, o que se observa em 2015 na área é o poder público e a câmara de vereadores legitimando a ocupação desse espaço, inclusive, conferindo licenças e até mesmo "certificados verdes" que ficam expostos na frente dos empreendimentos, como é o caso do Loteamento Brisas Mares do Sul, possível de ver na figura 1.

Figura 1 - Certificado Verde conferido ao Loteamento Brisas Mares do Sul

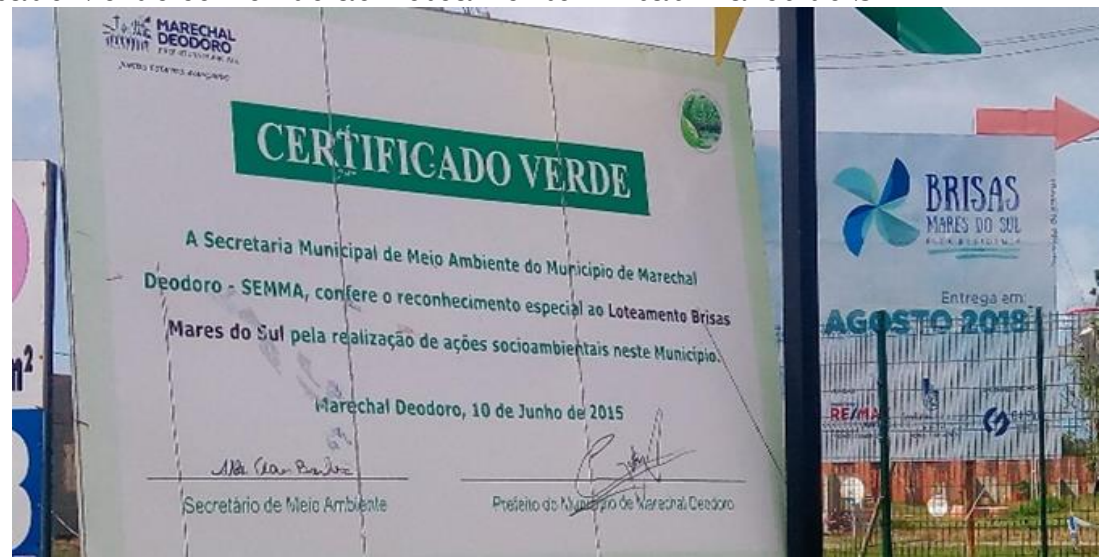

Fonte: Elaboração das autoras, 2018.

O caso mais emblemático sobre contradição entre regulamentos ambientais e licenças ambientais é o do loteamento Parque Brumas do Francês, na Praia do Saco, em processo de venda a partir de 2019 como "Saco da Pedra Beach Residence", que está sendo construído pela Nova Itália Construções LTDA ME. O loteamento tem 76,17 ha. e teve sua licença de número 015/97 concedida pelo Instituto do Meio Ambiente de Alagoas- IMA por tempo indeterminado em 1997.

Especificamente o loteamento Parque Brumas do Francês encontra-se em uma planície arenosa costeira alagoana, local onde está inserido o Complexo Estuarino Lagunar Mundaú/ Manguaba - CELMM, que é um mosaico de ambientes terrestres e aquáticos, foco de várias pesquisas acadêmicas, localizado no litoral centro do Estado de Alagoas (ALAGOAS, 2017). O loteamento está sendo construído na Zona de Recuperação Ambiental Compensatória - ZRAC e próximo 223 metros da Reserva Ecológica do Saco da Pedra - RESEC, ambas Unidades de Conservação estaduais. Conforme Plano de Manejo da APA, a ZRAC

Representam áreas onde a presença humana modificou consideravelmente ou definitivamente o local através de alterações do uso do solo, transformando ou comprometendo os processos naturais existentes no local. Consistem basicamente em construções irregulares em APP, aglomerados subnormais, construções em faixa non aedificandi, terrenos de marinha e ocupações consideradas incompatíveis verificadas em Zonas de Preservação e Conservação. O uso pela agricultura e pecuária de forma indiscriminada nas áreas descritas anteriormente também caracterizam essas áreas de incongruência (ALAGOAS, 2015, p. 245).

O parecer técnico do IMA no processo de número 6.847 de 2017 descreve quais são os usos compatíveis e permitidos, não compatíveis e não permitidos nessa zona, conforme quadro 1 , o que inclui "Quaisquer interferências antrópicas de dificultem ou impeçam a regeneração do ambiente, salvo em situações passíveis de regularização da atividade, previstas neste documento e em conformidade com o entendimento do IMA", contudo os empreendimentos continuam sendo licenciados. 
Quadro 1 - Usos compatíveis e permitidos ou não na ZRAC

\begin{tabular}{|c|l|}
\hline $\begin{array}{c}\text { Usos Compatíveis e } \\
\text { Permitidos }\end{array}$ & $\begin{array}{l}\text { 1.Reflorestamento; 2. Regularização da atividade ou } \\
\text { empreendimento, caso definido pelo IMA e Prefeitura Municipal } \\
\text { através de termo de compromisso com o proprietário, apresentação } \\
\text { de estudo ambiental, recuperação e compensação ambiental; 3. }\end{array}$ \\
& $\begin{array}{l}\text { Atividades voltadas à educação ambiental; 4. Utilização para } \\
\text { recuperação por passivos ambientais na APA. }\end{array}$ \\
\hline Usos Não & $\begin{array}{l}\text { Quaisquer interferências antrópicas de dificultem ou impeçam a } \\
\text { regeneração do ambiente, salvo em situações passíveis de } \\
\text { Pompativeis e Não } \\
\text { Permitidos }\end{array}$ \\
& $\begin{array}{l}\text { regularização da atividade, previstas neste documento e em } \\
\text { conformidade com o entendimento do IMA. }\end{array}$ \\
\hline
\end{tabular}

Fonte: ALAGOAS, 2015. Quadro elaborado pelas autoras, 2018.

O que se observa é que pelo zoneamento destinado à área, protegida por leis ambientais, esse tipo de licença não devia ter sido concedida, e nem o loteamento deveria ter sido regularizado. O Ministério Público Federal concedeu uma liminar em 2011 para a suspensão da construção do loteamento, como é possível observar na notícia do jornal primeira edição de 27 de março de 2012, contudo as obras continuam até hoje, porque nos processos posteriores houve a liberação do mesmo.

Em dezembro do ano passado, a pedido do Ministério Público Federal (MPF), a Justiça concedeu uma liminar para que as obras do Loteamento Parque Brumas do Francês (nome comercial Reserva das Tartarugas) fossem suspensas e que o Instituto do Meio Ambiente (IMA) paralisasse quaisquer procedimentos administrativos referentes a este licenciamento. De acordo com o relatório do Ibama, inúmeras infrações e crescentes impactos ambientais ilícitos que afetaram praias e terrenos de marinha, como o aterro de manguezais e faixas marginais de cursos d'água naturais foram cometidos pela empresa Nova Itália Construções Ltda. Houve a supressão de 5,7 hectares de vegetação nativa, em área de formação pioneira, de restinga, também inserida no Bioma Mata Atlântica, sendo efetuado ainda o corte raso de espécimes existentes, além da utilização de fogo. A Ação Civil Pública movida pelo MPF aponta que o empreendimento jamais deveria ter sido licenciado, pois, se situa em Áreas de Preservação Permanente (restinga e manguezais, bem como a 300 metros da preamar máxima) e, se não bastasse, essas APPs ainda se encontram inseridas em duas Unidades de Conservação (APA de Santa Rita e RESEC de Saco da Pedra) (OLIVEIRA; MARTINS, 2012, [S/N]).
Em 2018, como ainda estava no estágio de elaboração da estrutura do loteamento, o empreendimento ainda não tinha obtido a licença de operação, todavia havia iniciado as vendas dos lotes. O mesmo encontra-se cercado de tapumes de metal, por sugestão pelo órgão competente, mas as obras de terraplenagem no seu interior continuam sendo realizadas, liberadas, diga-se de passagem, pelo IMA, que aprovou o estudo de fauna e flora apresentados pelo proprietário do loteamento, alegando que a área já tinha perdido sua característica específica de restinga e não se enquadrava, desta forma, como Área de Proteção Permanente - APP de acordo com a definição do novo Código florestal.

Esse empreendimento vem ocasionando supressão vegetal de espécies locais preexistentes e aterro de mangue, como é possível observar na sequência de imagens de satélite (figura 2). Os impactos ambientais são incompatíveis com as determinações ZRAC. As imagens abaixo mostram a evolução do uso e ocupação do solo e a supressão vegetal de restinga ocorrida entre 2002 a 2017 na área ocupada pelo loteamento Parque Brumas do Francês. Ressalta-se aqui que não foi possível analisar essa área no período de licença (1997), visto que o EIA-RIMA foi perdido no órgão competente. É provável que com a finalização e vendas deste loteamento e de outras áreas em processo de estruturação, o espaço seja completamente ocupado, causando também a privatização das áreas públicas do loteamento e do acesso à praia.

Segundo a lei Federal n. 6.776/79, no art. 22 loteamentos fechados são proibidos "Desde a data de registro do loteamento, passam a integrar o domínio do Município as vias e praças, os espaços livres e as áreas destinadas a edifícios públicos e outros equipamentos urbanos, constantes do projeto e do memorial descritivo", Brasil (1979), contudo, isso tem sido uma prática, ocorrendo apropriação e privatização das áreas públicas com cercamento do loteamento. Isso já 
ocorre no "Residencial Ilha da Lagoa" e no "Residencial Granville", originalmente eram loteamento e posteriormente foram cercados por muros, grades e guaritas, e passam a ser denominados pelos incorporadores de residenciais como é possível observar na figura 3 .

A "privatização" do acesso à praia também já acontece na Praia do Saco, pois na linha da costa existem casas de alto padrão que se localizam a beira mar, sem nenhum arruamento, desrespeitando a distância necessária da linha da praia estabelecida pela legislação, cerceando o acesso dos moradores da comunidade do entorno, visto que alguns acessos são restritos e contam com a presença de vigilância 24h. Inclusive, alguns dos proprietários dessas casas têm sido geradores de grandes problemas ambientais, jogando entulhos de construção civil na praia por conta da construção de muros de contenção, e foram autuados pelo IMA em 2017, de acordo com a notícia publicada em pelo portal g1.globo.com, em fevereiro de 2017.

A área da praia é considerada de domínio público e tem leis estaduais e federais a serem consideradas como a 7661/88 e o decreto 5300/04 (que cria e institui o Plano Nacional de Gerenciamento Costeiro), Brasil (1988). Segundo a referida lei, em seu Art. 10. "As praias são bens públicos de uso comum do povo, sendo assegurado, sempre, livre e franco acesso a elas e ao mar, em qualquer direção e sentido (...)" Brasil (1988). Além disso, sabe-se que em 2010 foi criada a Política Nacional de Resíduos Sólidos - PNRS, lei Federal 12.305/10, que responsabiliza os geradores de resíduos da construção civil a gerenciá-los e a depender da quantidade apresentar junto ao órgão competente o plano de gerenciamento Brasil, (2010).

A expansão dos loteamentos tem ampliado os impactos socioambientais na região da Praia do Saco dentre eles: supressão vegetal (Mata Atlântica, Restinga e Manguezal) afetando a migração de pássaros e diminuindo a população de espécies da fauna; descarte irregular de resíduos sólidos, principalmente da construção civil que são encontrados na faixa da praia e entorno; lançamento de efluentes no canal da laguna Manguaba; ocupação irregular da faixa da praia e em outras áreas de proteção permanente, interferência na atividade pesqueira e na desova de tartarugas marinhas e desterritorialização das comunidades tradicionais.

Figura 2 A; B; C; D; E; F - Sucessão de imagens aéreas apresentando o processo de ocupação do empreendimento Brumas do Francês
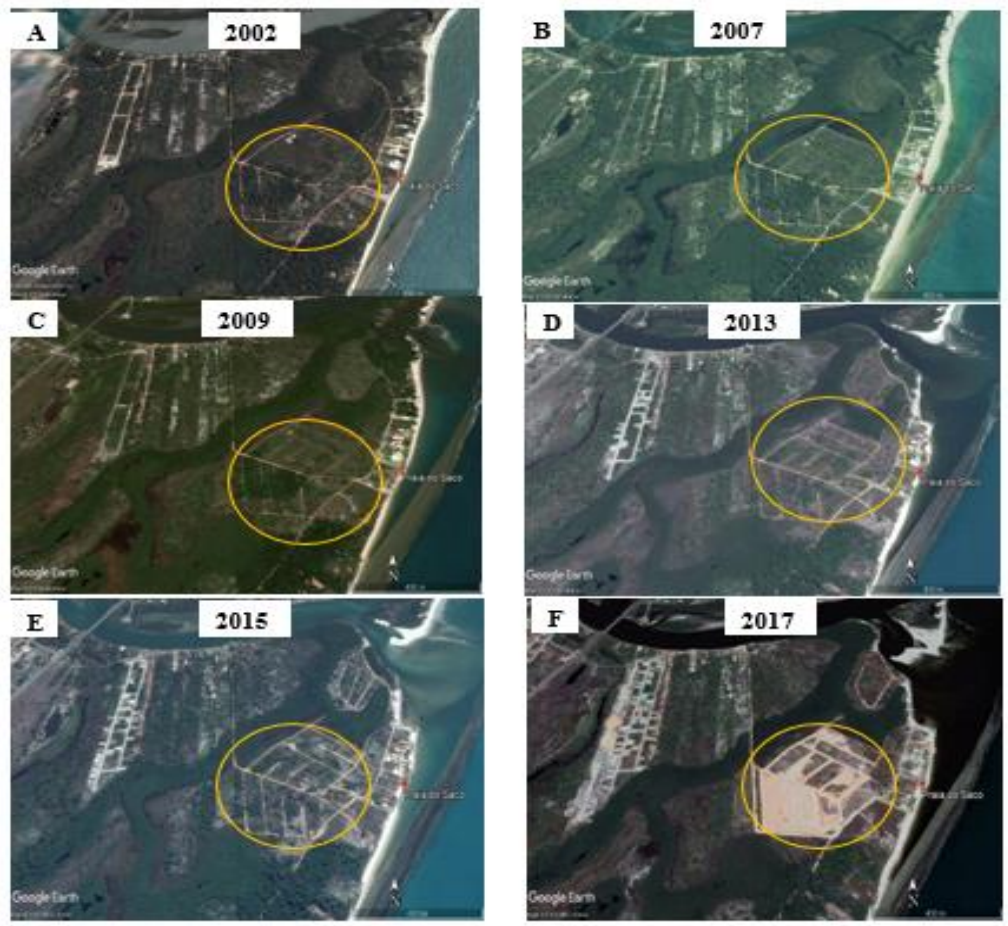

Fonte: Google Earth, 2017 
Figura 3 A e B - Residencial Ilha da Lagoa na Praia do Saco, como loteamento em 2012 (A) e em 2018 como condomínio fechado (B)

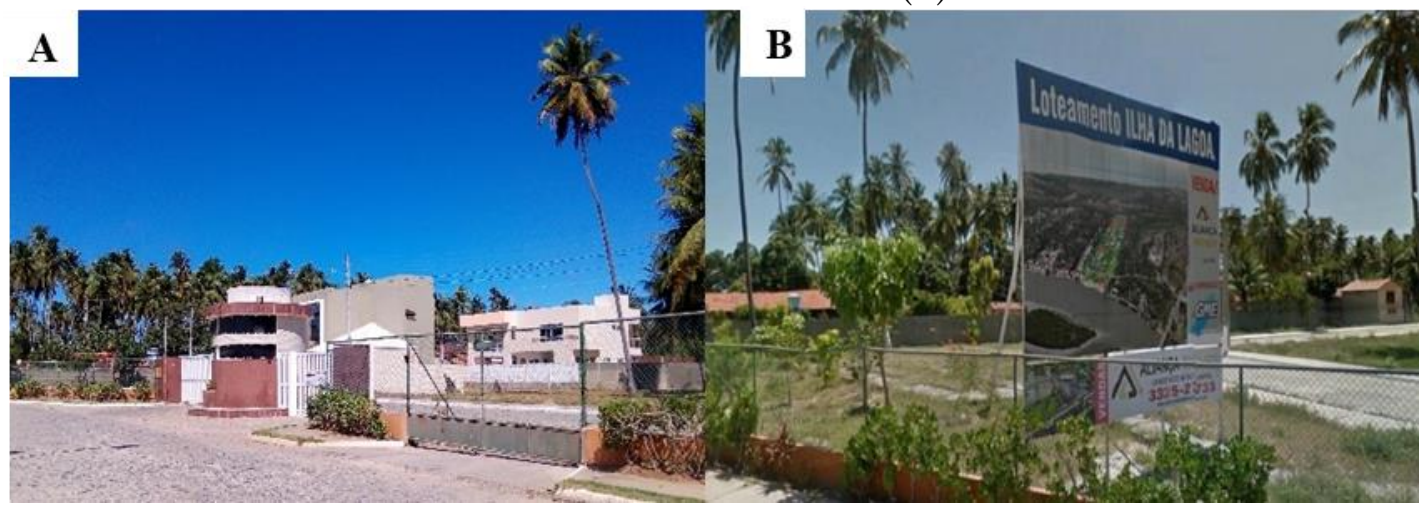

Fonte: Google Earth, 2012 Fonte: Elaboração das Autoras, 2018

Mesmo sendo uma área com restrições de uso, as especulações imobiliária e fundiária são bastante presentes. Nessa mesma região, existem terrenos cercados, aguardando as mudanças "melhorias" na infraestrutura local.

Esse aumento no uso e ocupação do solo por "residenciais" e loteamentos, onde se privatiza o espaço público em detrimento do privado, já afeta os moradores tradicionais do local e contribui para segregação socioespacial, pois forçam os visitantes ou moradores mais antigos da localidade a procurarem outros lugares para trabalho, moradia e lazer, interferindo, por exemplo, na atividade pesqueira, realizada na praia. Vale salientar que com a expansão desses equipamentos imobiliários de alto padrão os moradores da região têm mudado suas atividades econômicas originárias para prestar serviços a essas residências e estabelecimentos comerciais.

A ampliação dos empreendimentos imobiliários de alto padrão tem aumentado a segregação socioespacial e os problemas ambientais. Como afirma Carlos:

A violenta transformação das áreas onde se estabelecem os novos projetos expulsa os residentes e implanta um padrão estético homogêneo. $\mathrm{O}$ concreto e o vidro são utilizados para criar uma imagem do "moderno" nos novos edifícios voltados às atividades do setor de serviços e são criadas as formas condominiais nos setores residenciais. Com isso, uma nova "ordem" se estabelece a partir ação dos promotores imobiliários vinculada às estratégias do sistema financeiro que orienta e reorganiza o processo de reprodução espacial através da fragmentação dos espaços vendidos e comprados no mercado. (CARLOS, 2015, p. 27).
Esses fatores influenciam diretamente a classe trabalhadora que precisa desenvolver suas atividades e morar em espaços sem o mínimo de salubridade e muitas vezes impactados por grades empreendimentos, instalados para atender os interesses daqueles que detém a maior fatia do capital. Nessa lógica, comunidades tradicionais localizadas em áreas de interesse do circuito imobiliário são desterritorializadas.

Para tal, os empreendedores do mercado imobiliário junto com o Estado se articulam e promovem algumas estratégias para garantir a especulação imobiliária como aumento dos tributos referente à terra, compram terras e imóveis e os deixem por um certo tempo "vazios", ou seja, especulam a área enquanto o Estado promove melhorias estruturais. No caso da região da Praia do Saco, a comunidade que historicamente vive no local acaba sofrendo uma pressão pelos novos empreendimentos imobiliários. Muitas vezes a população mais pobre não consegue resistir a nova dinâmica imposta com a chegada dos condomínios e loteamentos e é espoliada, passando a ocupar as periferias socialmente vulneráveis.

A estética atribuída à mercadoria, no caso imobiliária, se utiliza dos elementos como raridades ou amenidades relacionadas à natureza para agregar valor e ampliar a acumulação do capital. Contudo, a expansão desses empreendimentos, com acontece na Praia do Saco, é inversamente proporcional à ideia de raridade e amenidades, o que torna esse processo de produção do espaço contraditório em sua essência, vistos os limites de exploração da natureza frente à transformação do espaço.

A atual estrutura social, baseada nas relações capitalistas, transforma tudo em mercadoria, essa estratégia, junto à exploração da natureza e da classe trabalhadora é ao mesmo tempo condição e contradição. Torna-se condição na medida em que os recursos naturais e a força 
laboral são essenciais para a manutenção e acumulação do capital, todavia, a busca incansável pela mais valia vem gerando conflitos e impactos socioambientais. Com isso nota-se a contaminação e poluição de solos, dos recursos hídricos, impactos na flora e na fauna e também produzindo consequências negativas para as condições de moradia e para a saúde da população. Esses impactos são evidentes na Praia do Saco, mesmo havendo todo aparato legal que teoricamente protege essas áreas de usos intensos.

\section{CONSIDERAÇÕES FINAIS}

O processo de acumulação de capital através da produção imobiliária tem destaque na reprodução contemporânea do capital. As formas de agregar valor à mercadoria na produção do espaço estão relacionadas a diversas estratégias dos incorporadores que despertam desejos específicos aos compradores em potencial. Esse é um processo totalizante, porém com suas particularidades de acordo com as configurações do sítio e da construção histórica do local. No caso da Praia do Saco a natureza, a proximidade do centro de Maceió e o discurso de sustentabilidade aparecem como elementos centrais na composição da estética dessa mercadoria tão cara e tão restrita. No entanto, a relação com a natureza se apresenta contraditória, pois o discurso tende para preservação e conservação desses espaços, mas a prática revela um processo inverso, de grande impacto socioambiental.

Neste caso da Praia do Saco, como em muitos outros, o Estado se apresenta como um agente importante, o qual poderia se apresentar como normatizador e regulador das ações dos agentes imobiliários, restringindo as licenças e fiscalizando as arbitrariedades, mas acaba exercendo o papel legitimador das infrações que se estabelecem ao longo da implantação dos loteamentos na Massagueira. É evidente que cada vez mais os representantes do Estado têm agido como mediadores dos interesses privados na produção do espaço urbano, legislando a favor de ações específicas, ou contraditoriamente não aplicando as leis que restringem os usos de certas áreas, como foi possível verificar no caso da Praia do Saco em relação à legislação ambiental.

É muito clara a intenção dos incorporadores na utilização de um discurso distópico, baseado em uma falsa verdade, que vende uma coisa, mas realiza outra, como no caso de associar a natureza e a sustentabilidade ambiental a um empreendimento que causa um enorme impacto ambiental já em sua implementação. Essa estratégia não é mais uma novidade no que tange o valor de troca com fins de ampliação do lucro. O agente hegemônico não é apenas o incorporador, mas também o comprador dos imóveis, pois a ideia de valor de uso como simples interesse do comprador para o uso da mercadoria, no caso um imóvel para a moradia, não é suficiente.

$\mathrm{O}$ que se percebe são diversos significados sociais promovidos pelos os signos agregados aos imóveis, pois se trata de uma sociedade de classes, em que não é apenas o uso que está em questão, mas a apropriação restrita, a raridade, a distinção, a exclusividade de uso e acesso à mercadoria e aos elementos que a rodeia, como neste caso, a natureza de uma área costeira, e é diante disse que a segregação se estabelece, produzindo processos de espoliação e desterritorialização daqueles que se estabeleceram anteriormente nessas áreas mas não conseguem se inserir na nova dinâmica produzida pela transformação desse espaço.

Diante do exposto foi possível constatar que este processo de expansão imobiliária no litoral sul da Região Metropolitana de Maceió tem reproduzido o processo de acumulação por despossessão, pois com o intuito de produção desses empreendimentos com o fim de reprodução e acumulação do capital, áreas são apropriadas pelos empreendedores e comunidades tradicionais são expulsas direta ou indiretamente. Essas ações têm interferido diretamente na conservação dos recursos naturais e principalmente na relação das comunidades tradicionais com o ambiente que garantiu a subsistência. O que aparenta é que essas áreas de proteção ambiental acabam se configurando como reservas de terras para ação dos agentes hegemônicos da produção do espaço, uma articulação entre capitalistas e Estado em um jogo de regularização do uso das terras para fins específicos.

\section{REFERÊNCIAS}

\author{
ALAGOAS. Plano de Manejo da Área de \\ Proteção Ambiental de Santa Rita. \\ Disponível em: <http://ima.al.gov.br/wp- \\ content/uploads/2015/03/Plano-de-Manejo-APA- \\ Santa-Rita-IMA-Alagoas.pdf $>$. Acesso em 26 de \\ março de 2020.
}


ALAGOAS. Processos de Autorização Ambiental de Loteamento Parque Brumas do Francês, no 6847 e 6849 de 2017. Instituto do Meio Ambiente - IMA, 2017

BRASIL. Lei $\mathbf{n}^{\mathbf{0}} \mathbf{1 2 . 3 0 5}$, de 2 de agosto de 2010. Política Nacional de Resíduos Sólidos. Presidência da República, Departamento da Casa Civil. Brasília, 2010.

. Lei $n^{\circ}$ 6.766, de 19 de dezembro de

1979. Dispõe sobre o Parcelamento do Solo Urbano e dá outras providências. Brasília: Senado, 2001.

. Lei $\mathrm{n}^{\circ}$ 7.661, de 16 de maio de 1988 .

Plano Nacional de Gerenciamento Costeiro. Presidência da República, Departamento da Casa Civil. Brasília, 1988.

CARLOS, Ana Fani Alessandri. A cidade. São Paulo: Contexto, 1999.

(org). A crise urbana. Ed.São Paulo: Contexto, 2015.

G1 AL. Restos de Construção são deixados na Praia do Saco, Marechal Deodoro. Disponível

em: <http://g1.globo.com/al/alagoas/noticia/2017/02/ restos-de-construcao-sao-deixados-na-praia-dosaco-marechal-deodoro.html>. Acesso em 29 de agosto de 2018.

HAUG, F. W. Crítica da Estética da Mercadoria. Ed. São Paulo: Unesp, 1996.

HARVEY, D. A produção capitalista do espaço. São Paulo: Annablume, 2001.

HELENO, S. Ecos, Ecos, Ecos Deodorenses. Marechal Deodoro: [s.n], 2009.

IBGE - Instituto Brasileiro de Geografia e Estatística. Panorama de Marechal Deodoro. Disponível em: <https://cidades.ibge.gov.br/brasil/al/marechaldeodoro/panorama>. Acesso em 10 de julho de 2018.

LEFEBVRE, H. A revolução Urbana. Tradução de Sérgio Martins. Ed. Belo Horizonte: UFMG, 2004.

LENCIONI, S. Metrópole e sua lógica capitalista atual face ao regime de acumulação patrimonial. In: LENCIONI, S.; BLANCO, J. (Orgs). Argentina e Brasil: Territórios em Definição. Rio de Janeiro: Consequência, 2016.

MACHADO, C. G. Vilegiatura maritima e urbanização litorânea: as transformações no litoral sul do município da Barra de São Miguel, AL. Dissertação (Mestrado em Dinâmicas do Espaço Habitado) - Maceió: UFAL, 2016.

OLIVEIRA, M.; MARTINS, L. Construtoras ignoram a lei e mudam a paisagem de Áreas de Preservação Permanente. Jornal
Primeira Edição. Disponível em: <http://primeiraedicao.com.br/noticia/2012/04/2 7/construtoras-.ignoram-a-lei-e-mudam-apaisagem-de-areas-de-preservacaopermanente.27/04/2012>. Acesso em 29 de agosto de 2018.

MARECHAL DEODORO, Prefeitura de. Lei 919 de 09 de novembro de 2006 que corresponde ao Plano Diretor Municipal de Marechal Deodoro. Marechal Deodoro: Câmara de Vereadores, 2006.

SCHIMDT, A. El concepto de Naturaleza em Marx. México: siglo XXI, 1977.

VIEIRA, M. do C. Daqui só saio o pó: conflitos urbanos e mobilização popular: a Salgema e o Pontal da Barra. Maceió: EDUFAL, 1997. 